\title{
Genomic associations with somatic cell score in first-lactation Holstein cows
}

\author{
S. Wijga, ${ }^{\star 1}$ J. W. M. Bastiaansen, ${ }^{\star}$ E. Wall,† E. Strandberg,‡ Y. de Haas,§ L. Giblin,\# and H. Bovenhuis ${ }^{\star}$ \\ ${ }^{*}$ Animal Breeding and Genomics Centre, Wageningen University, PO Box 338, 6700 PG, Wageningen, the Netherlands \\ †Sustainable Livestock Systems Group, Scottish Agricultural College, Easter Bush, Midlothian, EH25 9RG, United Kingdom \\ ¥Department of Animal Breeding and Genetics, Swedish University of Agricultural Sciences, PO Box 7023, S-750 07 Uppsala, Sweden \\ §Animal Breeding and Genomic Centre, Wageningen UR Livestock Research, PO Box 65, 8200 AB, Lelystad, the Netherlands \\ \#Teagasc, Moorepark Food Research Centre, Fermoy, Co. Cork, Ireland
}

\section{ABSTRACT}

This genome-wide association study aimed to identify loci associated with lactation-average somatic cell score (LASCS) and the standard deviation of test-day somatic cell score (SCS-SD). It is one of the first studies to combine detailed phenotypic and genotypic cow data from research dairy herds located in different countries. The combined data set contained up to 52 individual test-days per lactation and thereby aimed to capture temporary increases in somatic cell score associated with infection. Phenotypic data for analysis consisted of 46,882 test-day records on 1,484 cows, and genotypic data consisted of 37,590 single nucleotide polymorphisms (SNP). Using an animal model, the associations between each individual SNP and the phenotypic data were estimated. To account for the risk of false positives, a false discovery rate threshold of 0.20 was set. The analyses showed that LASCS was significantly associated with a SNP on Bos taurus autosome (BTA) 4 and a SNP on BTA18. Likewise, SCS-SD was associated with this SNP on BTA18. In addition, SCS-SD significantly associated with a SNP on BTA6. Relatively few associations were found, suggesting that LASCS and SCS-SD are controlled by multiple loci distributed across the genome, each with a relatively small effect. Increased knowledge on genetic regulation of LASCS and SCS-SD may aid in identification of genes that play a role in mastitis resistance. Such knowledge helps us understand the genetic mechanisms leading to mastitis and in discovery of targets for mastitis therapeutics.

Key words: genome wide, dairy cow, single nucleotide polymorphism, mastitis

\section{INTRODUCTION}

In the last decade, mastitis resistance has become an important breeding objective in dairy cattle from

\footnotetext{
Received July 11, 2011.

Accepted October 13, 2011.

${ }^{1}$ Corresponding author: susan.wijga@wur.nl
}

an economical and animal welfare perspective (Miglior et al., 2005; Rupp et al., 2007). Somatic cell count is the commonly used indirect measure of mastitis (e.g., Rupp and Boichard, 2003; Detilleux, 2009). Although SCC shows relatively large genetic variation (Rupp and Boichard, 2003), heritabilities for SCC are low to moderate (Rupp and Boichard, 2003) and a genetic antagonism exists between SCC and production traits (e.g., Rupp and Boichard, 1999; Carlén et al., 2004). As such, and combined with the fact that SCC can only be measured on cows and not on bulls, selection for mastitis resistance could benefit from genomic information. Genomic information may be particularly useful for increasing the accuracy of the EBV of bull dams, which is currently based on own performance.

The recent discovery of millions of SNP in livestock genomes (Matukumalli et al., 2009), forming dense marker maps, and a concurrent substantial decrease in genotyping costs (Daetwyler et al., 2008; Hayes et al., 2009) have created opportunities for the use of genomic information, allowing for genome-wide association studies (GWAS; Hirschhorn and Daly, 2005). Results from GWAS may not only identify markers that enable more accurate breeding value estimation but also aid in the understanding of genetic control of traits through identification of genes (e.g., Pryce et al., 2010). So far, GWAS for dairy cattle are limited and GWAS that are reported have been performed on traits routinely recorded in commercial dairy herds using daughter yield deviations or EBV of progeny-tested bulls. The present study used combined phenotypic and genotypic data of first-lactation Holstein cows from 4 European research herds. These herds provide more detailed SCC recordings (up to 52 individual test-days per lactation) compared with commercial herds, where SCC is usually recorded monthly. These detailed recordings provide a more comprehensive representation of the phenotype. In addition, the use of genotypic data on cows allows estimation of dominance effects, which is not possible when using daughter yield deviations.

Generally, genetic selection is based on lactationaverage SCC. Lactation-average SCC, however, does 
not capture variation in SCC levels during lactation (de Haas et al., 2003). As suggested by Urioste et al. (2010) and Green et al. (2004), the standard deviation of test-day SCC largely reflects this variation and aims to capture temporary increases in SCC associated with infection. The standard deviation of test-day SCC is genetically variable and strongly associated with clinical mastitis (CM; Urioste et al., 2010). Therefore, it is an interesting candidate in selection for mastitis resistance (Urioste et al., 2010).

The present study aimed to identify loci associated with lactation-average SCS and the standard deviation of test-day SCS through a GWAS using combined phenotypic and genotypic data of first-lactation Holstein cows from 4 European research herds.

\section{MATERIALS AND METHODS}

The present study was part of the RobustMilk project funded by the European Union, a collaboration between 6 European research institutes (www.robustmilk.eu). The RobustMilk project combined unique phenotypic and genotypic data from 8 research dairy herds located in 4 European countries: 3 herds in Ireland (McCarthy et al., 2007), 2 herds in the Netherlands (Veerkamp et al., 2000), 2 herds in Scotland (Bell et al., 2011), and 1 herd in Sweden (Petersson et al., 2006). The Scottish cows belonged to 2 genetic lines (Veerkamp et al., 1994) and were therefore treated as 2 separate herds. At the time of data recording, some cows included in the RobustMilk project were subjected to dietary treatments as part of other studies. Data were recorded between October 1989 and September 2009.

\section{Genotypes}

DNA was extracted from blood samples and cows were subsequently genotyped for 54,001 SNP by a commercial genotyping company (ServiceXS, Leiden, the Netherlands) using the Illumina BovineSNP50 BeadChip (Illumina Inc., San Diego, CA). The SNP genotypes were scored using Illumina BeadStudio software (v3.3.4). Quality control was performed on the genotypic data of the separate countries, using criteria set by Hayes et al. (2009) with minor modifications. A SNP was included in the data set when the following criteria were met: (1) the minor allele frequency (MAF) was $>1 \%$ in each country; (2) the percentage of missing genotypes for the SNP across all samples was $<5 \%$; (3) the Gen Train score (statistical score for accuracy of clustering) was $>0.55$ and the Gen Call score (statistical score for genotyping accuracy) was $>0.20$; and (4) the SNP did not deviate strongly from Hardy-Weinberg equilibrium (Hardy Weinberg $x^{2}$ values $<600)$. A SNP that failed a criterion in at least one country was discarded from the complete data set. Furthermore, animals with SNP call rates $<95 \%$ were removed from the data set $(\mathrm{n}=70)$. In total, 37,590 SNP were retained and were thus available for analyses. These SNP were distributed over the Bos taurus genome as shown in Table 1. All animals genotyped within the RobustMilk project were checked for pedigree inconsistencies using the methodology outlined by Calus et al. (2011).

\section{Animals and Phenotypes}

Phenotypic data were compiled from cows that passed the genotype quality control and pedigree check. This data set consisted of 81,408 first-lactation test-day records on 1,816 Holstein cows. Test-day records with SCC greater than zero recorded before 350 DIM were retained. Cows that had fewer than 10 SCC test-day records were discarded so that sufficient records were available for estimating mean and standard deviations of SCC.

Table 1. Distribution of SNP available for analyses over Bos taurus chromosomes (Chr.) and the size of the individual chromosomes ${ }^{1}$

\begin{tabular}{|c|c|c|}
\hline Chr. & $\begin{array}{c}\text { Size } \\
\text { (Mbp) }\end{array}$ & $\begin{array}{l}\text { No. of } \\
\text { SNP }\end{array}$ \\
\hline Null & Unassigned & 1,089 \\
\hline 1 & 161.1 & 2,302 \\
\hline 2 & 140.8 & 1,911 \\
\hline 3 & 127.9 & 1,810 \\
\hline 4 & 124.5 & 1,775 \\
\hline 5 & 125.8 & 1,498 \\
\hline 6 & 122.6 & 1,771 \\
\hline 7 & 112.1 & 1,547 \\
\hline 8 & 116.9 & 1,643 \\
\hline 9 & 108.1 & 1,452 \\
\hline 10 & 106.4 & 1,542 \\
\hline 11 & 110.2 & 1,587 \\
\hline 12 & 85.4 & 1,170 \\
\hline 13 & 84.4 & 1,275 \\
\hline 14 & 81.3 & 1,189 \\
\hline 15 & 84.6 & 1,185 \\
\hline 16 & 77.9 & 1,135 \\
\hline 17 & 76.5 & 1,107 \\
\hline 18 & 66.1 & 927 \\
\hline 19 & 65.3 & 972 \\
\hline 20 & 75.8 & 1,085 \\
\hline 21 & 69.1 & 968 \\
\hline 22 & 61.8 & 942 \\
\hline 23 & 53.4 & 761 \\
\hline 24 & 65.3 & 885 \\
\hline 25 & 44.1 & 709 \\
\hline 26 & 51.8 & 743 \\
\hline 27 & 48.7 & 692 \\
\hline 28 & 46.1 & 647 \\
\hline 29 & 60.0 & 773 \\
\hline $\mathrm{X}$ & 88.5 & 498 \\
\hline Total SNP & & 37,590 \\
\hline
\end{tabular}

${ }^{1}$ Based on Baylor 4.0/bosTau4 assembly. 
The edited phenotypic data used for the association study consisted of 46,882 first-lactation test-day records on 1,484 genotyped Holstein cows located in 4 countries: Ireland $(\mathrm{n}=329$ cows; 8,795 test-day records), the Netherlands ( $\mathrm{n}=574$ cows; 17,024 testday records), Scotland ( $\mathrm{n}=390$ cows; 13,312 test-day records), and Sweden ( $\mathrm{n}=191$ cows; 7,751 test-day records).

Lactation-average SCC and test-day SCC standard deviation were calculated for each cow based on her test-day records. The number of test-day records per cow ranged between 10 and 52 with an average of 31 test-days. Lactation-average SCC was log-transformed (Ali and Shook, 1980) to lactation-average SCS (LASCS):

$$
\mathrm{LASCS}=\log _{2}\left(\frac{\sum S C C}{n}\right)
$$

Test-day SCC standard deviation was log-transformed in a similar manner into test-day SCS standard deviation (SCS-SD):

$$
\mathrm{SCS}-\mathrm{SD}=\log _{2}\left(\frac{\sum(S C C-\mu)^{2}}{n-1}\right),
$$

where $\mu$ was the mean test-day SCC and $n$ was the number of test-day records.

In summary, the data for analyses consisted of 46,882 SCC test-day records on 1,484 first-lactation Holstein cows. For all cows, genotypic information consisted of 37,590 SNP. The approval of the Dutch Animal Care and Use committee was not needed, as data used in the present study were obtained from existing databases.

\section{Statistical Analyses}

Genetic and residual variances for LASCS and SCSSD were estimated with a bivariate linear animal model using the ASReml software package (version 3; Gilmour et al., 2009). Data were analyzed with the following model:

$$
y_{i j k}=\mu+\text { CHYST }_{i}+\text { Byear }_{j}+\text { Animal }_{k}+e_{i j k},
$$

where $y_{i j k}$ is the response variable corresponding to LASCS and SCS-SD of cow $k$ from CHYST-group $i$ born in year $j ; \mu$ is the overall mean; $C H Y S T_{i}$ was a fixed effect accounting for the combination $i$ of country (C) and herd $(\mathrm{H})$ in which the record was produced, year $(\mathrm{Y})$ and season $(\mathrm{S})$ of calving of the cow producing the record, and dietary treatment $(\mathrm{T})$ the cow received during lactation ( $i=1$ to 146). Seasons were defined as calendar quarters (January to March, April to June, July to September, and October to December); CHYST groups containing $<5$ individuals were merged with adjacent CHYST groups; Byear $r_{j}$ was a fixed effect accounting for the year of birth $j$ of the cow ( $j=1$ to 23 ); Animal $_{k}$ was the random additive genetic effect of animal $k$ distributed as $\sim N\left(\mathbf{0}, \mathbf{A} \sigma_{a}^{2}\right)$, which accounted for (co)variances between animals due to genetic relationships by formation of a matrix $\mathbf{A}$ based on pedigree records; the pedigree consisted of 9,368 individuals over 19 generations; $e_{i j k}$, distributed as $\sim N\left(\mathbf{0}, I \sigma_{e}^{2}\right)$, was the random residual effect.

Heritabilities were calculated as

$$
h^{2}=\frac{\sigma_{a}^{2}}{\sigma_{a}^{2}+\sigma_{e}^{2}},
$$

where $\sigma_{a}^{2}$ represented the additive genetic variance and $\sigma_{e}^{2}$ the residual variance.

The genetic correlation was calculated as

$$
r_{g}=\frac{\sigma_{a L A S C S, a S C S-S D}^{2}}{\sqrt{\left(\sigma_{a L A S C S}^{2} \times \sigma_{a S C S-S D}^{2}\right)}},
$$

where $\sigma_{a L A S C S}^{2}$ was the additive genetic variance for LASCS, $\sigma_{a S C S-S D}^{2}$ was the additive genetic variance for SCS-SD, and $\sigma_{a L A S C S, a S C S-S D}^{2}$ was the additive genetic covariance between LASCS and SCS-SD.

The association of each individual SNP with the phenotype was estimated from a univariate linear animal model using ASReml (version 3; Gilmour et al., 2009). The data were analyzed following model [3], with the addition of a fixed single SNP effect to the model. The consequence of this analysis is that SNP in linkage disequilibrium with the causative mutation will all show an effect. The heritabilities for LASCS and SCS-SD were fixed at the estimate obtained from the preceding bivariate analyses, for ease of computation, which is valid when SNP effects are relatively small.

To assess the effect of population substructure in the present data set, the single SNP analysis was also performed without the random additive genetic effect of the animal included in the model. The SNP variances were calculated based on the genotype frequencies and the estimated genotype effects.

\section{Multiple Testing}

In the single SNP association analyses, the significance of each individual SNP was tested, resulting in 
a multiple testing problem. Multiple testing increases the risk of false positives and to account for this, a false discovery rate (FDR) was used. The $P$-value threshold corresponding to an FDR of 0.20 was calculated, based on the $P$-value for each SNP obtained from the single SNP analysis using the package "qvalue" in the statistical environment R (Storey and Tibshirani, 2003). The SNP with $P$-values less than or equal to the $P$-value corresponding to the FDR were considered significantly associated with the phenotype.

\section{RESULTS}

\section{Descriptive Statistics and Genetic Parameters}

Mean LASCS, mean SCS-SD, and the corresponding standard deviation for the combined data set as well as the individual countries within the RobustMilk data set are shown in Table 2. Standard deviations in the separate countries were within $30 \%$ of the mean LASCS and SCS-SD of the combined data. The heritability estimated for LASCS was $0.17(\mathrm{SE}=0.06)$ with a phenotypic variance of 1.62 , and the heritability estimated for SCS-SD was $0.14(\mathrm{SE}=0.06)$ with a phenotypic variance of 3.2. The phenotypic correlation between LASCS and SCS-SD was 0.89 $(\mathrm{SE}=0.01)$ and the genetic correlation between LASCS and SCS-SD was estimated at $0.96(\mathrm{SE}=0.04)$.

\section{Association of SNP with LASCS}

The GWAS showed a significant association with LASCS on BTA4 and on BTA18 (Figure 1). On BTA4, SNP BTB-01841922 (ss64858711) showed a significant effect with a $-\log _{10} P$-value of 5.1.On BTA18, SNP ARS-BFGL-NGS-101491 (ss86330740) showed a significant effect with a $-\log _{10} P$-value of 5.6.

For SNP BTB-01841922, the genotype class with the smallest number of observations (AA) consisted of 13 cows, of which 12 were from Ireland. The MAF for this SNP was 0.11. Because AA animals came primarily from one country, the sensitivity of the analysis was tested by omitting cows belonging to the AA genotype

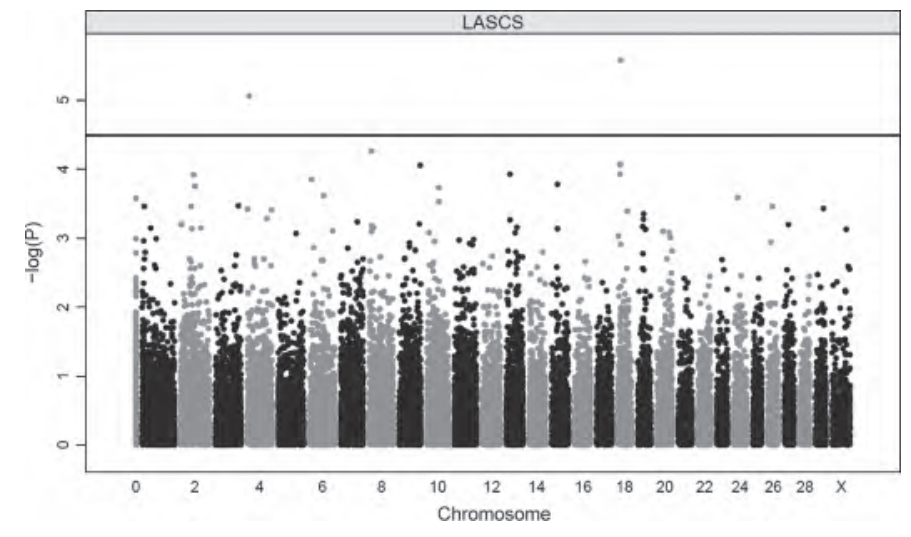

Figure 1. $-\log _{10} P$-values from single SNP analysis for lactationaverage SCS (LASCS). Chromosomes are arranged from left to right from chromosome 0 (unassigned SNP) to chromosome X. SNP above the black horizontal line passed the 0.20 false discovery rate threshold.

class. This retest resulted in an increase in $-\log _{10} P$-value from 5.1 to 5.7. $-\log _{10} P$-values and the genetic variance explained by the 2 significantly associated SNP are given in Table 3. Estimated SNP effects for the LASCSassociated SNP in the combined RobustMilk data set as well as in the separate populations are shown in Table 4. In general, estimated SNP effects in individual countries were in the same direction for each genotype class as the combined RobustMilk data, although effect sizes differed. These differences were, however, not significant $(\alpha=0.10)$. For SNP BTB-01841922 on BTA4, the homozygote genotype class with the largest number of observations (BB) consistently resulted in a lower LASCS than the heterozygote genotype class. Analysis of the untransformed SCC data showed that the SNP effect of -0.44 for this homozygote genotype class corresponded to a lower LASCS of approximately 51,000 cells $/ \mathrm{mL}$ compared with the heterozygote genotype class. For SNP ARS-BFGL-NGS-101491 on BTA18, the homozygous genotype class with the smallest number of observations (AA) resulted in the highest LASCS, whereas the homozygous genotype class (BB) with the largest number of observations resulted in the lowest LASCS. Ireland and Scotland showed a slight deviation from this pattern (Table 4), but these devia-

Table 2. Mean, standard deviation, and number of animals (n) for lactation-average SCS (LASCS) and the standard deviation for test-day SCS (SCS-SD) for the combined data (RobustMilk) and for each separate country of origin of the cows included in the data

\begin{tabular}{lccccccc}
\hline & & \multicolumn{2}{c}{ LASCS } & & \multicolumn{2}{c}{ SCS-SD } \\
\cline { 3 - 4 } \cline { 6 - 7 } Data & $\mathrm{n}$ & Mean & $\mathrm{SD}$ & & Mean & SD \\
\hline RobustMilk & 1,484 & 6.4 & 1.3 & & 6.3 & 1.9 \\
Ireland & 329 & 6.7 & 1.3 & & 6.7 & 1.7 \\
The Netherlands & 574 & 6.3 & 1.4 & & 6.2 & 1.9 \\
Scotland & 390 & 6.0 & 1.2 & & 5.9 & 1.9 \\
Sweden & 191 & 6.8 & 1.3 & & 6.9 & 1.8 \\
\hline
\end{tabular}


Table 3. Single nucleotide polymorphisms significantly associated (false discovery rate $<0.20$ ) with lactationaverage SCS (LASCS) and the standard deviation for test-day SCS (SCS-SD), their location on BTA, $-\log _{10}$ $P$-value $\left(-\log _{10} P\right)$, and the proportion of genetic variance explained by the SNP (Var)

\begin{tabular}{llrrrr}
\hline BTA & SNP & Location & & & \\
$(\mathrm{bp})$ & Trait & $-\log _{10} P$ & Var \\
\hline 4 & BTB-01841922 & $11,369,399$ & LASCS & 5.1 & 0.11 \\
$6^{1}$ & BTB-02087354 & $8,658,351$ & SCS-SD & 6.1 & 0.14 \\
18 & ARS-BFGL-NGS-101491 & $12,785,002$ & SCS-SD & 5.8 & 0.16 \\
18 & ARS-BFGL-NGS-101491 & $12,785,002$ & LASCS & 5.6 & 0.15 \\
\hline
\end{tabular}

${ }^{1} \mathrm{SNP}$ consisted of 2 genotype classes.

tions were not significant $(\alpha=0.10)$. Analyses of the untransformed combined RobustMilk data showed that the implication of the AA genotype for this SNP was an additional 87,000 cells $/ \mathrm{mL}$ compared with the BB genotype.

The MAF for BTB-01841922 was 0.11 in the total data set and remained relatively stable over birth years 1991 to 2007. The minor allele, A, was the unfavorable allele, resulting in an increased LASCS. The MAF for ARS-BFGL-NGS-101491, allele A, was 0.27 and fluctuated over birth years, from a minimum of 0.05 to a maximum of 0.34 . Also for this SNP, the minor allele was the unfavorable allele.

\section{Association of SNP with SCS-SD}

The GWAS for SCS-SD showed 2 SNP (Figure 2) with an FDR $\leq 0.20$. The SNP ARS-BFGL-NGS-101491 on BTA18, previously associated with LASCS, had a $-\log _{10} P$-value of 5.8 for SCS-SD. On BTA6, SNP BTB-02087354 (ss65101233) had a $-\log _{10} P$-value of 5.3. As part of the genotype quality control, SNP with a MAF $\leq 1 \%$ were removed from the data set. For SNP BTB-02087354, however, this could not prevent a genotype class (BB) with only one cow. For this reason, the analysis was repeated without this cow. As a result, the $-\log _{10} P$-value of association increased from 5.3 to 6.1. $-\log _{10} P$-values and the genetic variance explained by the 2 significantly associated SNP are given in Table 3. Estimated SNP effects for the SCS-SD-associated SNP in the total RobustMilk data set as well as in the separate populations are shown in Table 5. For SNP BTB-02087354 on BTA6, the heterozygous genotype class resulted in the highest SCS-SD compared with the homozygous genotype class, with the exception of Sweden. Analysis of the untransformed SCC data showed that SCS-SD was approximately 235,000 cells $/ \mathrm{mL}$ higher in the heterozygous genotype class compared with the homozygous genotype class. For SNP ARS-BFGLNGS-101491 on BTA18, the smallest homozygote genotype class (AA) resulted in the highest SCS-SD, and the largest homozygote genotype class $(\mathrm{BB})$ resulted in the lowest SCS-SD, with the exception of Scotland, where the heterozygous genotype class resulted in the highest SCS-SD. Analyses of the untransformed SCC data, using the combined RobustMilk data, showed that the AA genotype resulted in a 197,000 cells $/ \mathrm{mL}$ increase in SCS-SD compared with the BB genotype. The MAF for SNP BTB-02087354 was 0.02 and remained stable over the birth years tested.

\section{Polygenic Component}

All analyses in the present study included a polygenic component to account for family relationships between cows and population substructure caused by these relationships. In contrast to the LASCS analysis including a polygenic component (Figure $3 b$ ), a quantile-quantile plot for the LASCS analysis without a polygenic component showed many spurious SNP effects as deviations from the expected null distribution of the $P$-values and did therefore show an effect of population substructure

Table 4. Effect sizes per genotype class for SNP BTB-01841922 and ARS-BFGL-NGS-101491 significantly associated with lactation-average SCS (corresponding SE in parentheses) for the combined RobustMilk data and for each separate country of origin

\begin{tabular}{|c|c|c|c|c|c|c|}
\hline \multirow[b]{2}{*}{ Data } & \multicolumn{3}{|c|}{ BTB-01841922 } & \multicolumn{3}{|c|}{ ARS-BFGL-NGS-101491 } \\
\hline & $\mathrm{AA}$ & $\mathrm{AB}$ & $\mathrm{BB}$ & $\mathrm{AA}$ & $\mathrm{AB}$ & $\mathrm{BB}$ \\
\hline RobustMilk & $-0.45(0.37)$ & 0 & $-0.44(0.09)$ & $0.29(0.15)$ & 0 & $-0.32(0.08)$ \\
\hline Ireland & $0.19(0.37)$ & 0 & $-0.18(0.15)$ & $0.44(0.26)$ & 0 & $0.27(0.16)$ \\
\hline The Netherlands & - $^{1}$ & 0 & $-0.64(0.15)$ & $0.41(0.26)$ & 0 & $-0.30(0.26)$ \\
\hline Scotland & $-^{2}$ & 0 & -0.34 & $-0.05(0.30)$ & 0 & $-0.19(0.14)$ \\
\hline Sweden & $-^{2}$ & 0 & -0.28 & $0.24(0.49)$ & 0 & $-0.47(0.48)$ \\
\hline
\end{tabular}

${ }^{1}$ Genotype class consisted of 1 cow.

${ }^{2}$ No cows were present in this genotype class. 


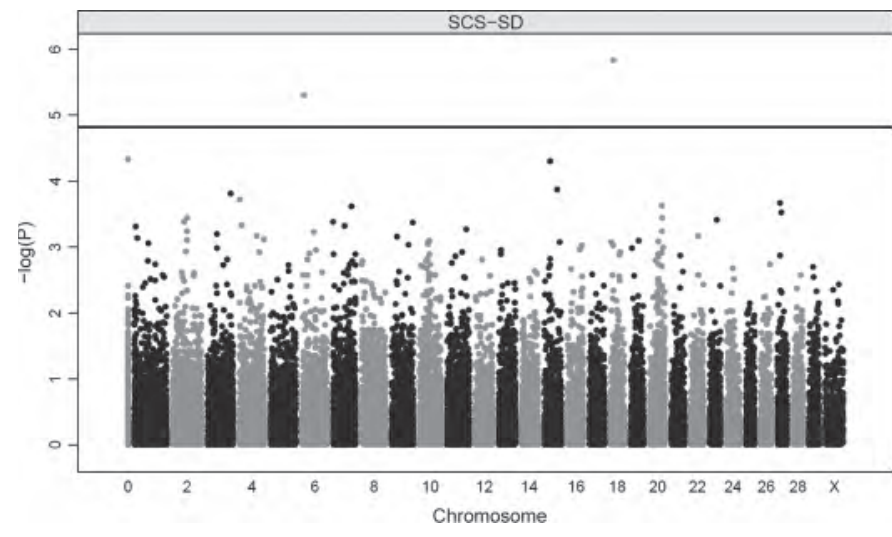

Figure 2. $-\log _{10} P$-values from single SNP analysis for test-day SCS standard deviation (SCS-SD). Chromosomes are arranged from left to right from chromosome 0 (unassigned SNP) to chromosome X. SNP above the black horizontal line passed the 0.20 false discovery rate threshold.

(Figure 3a). The same was true for SCS-SD (results not shown).

\section{DISCUSSION}

The objective of this GWAS was to identify loci associated with LASCS and SCS-SD using cow data. Few countries routinely record mastitis events, which hinders direct selection for mastitis resistance (Rupp and Boichard, 1999). Instead, the common practice is to use SCC or SCS as an indirect selection for mastitis (e.g., Rupp and Boichard, 2003). In commercial dairy herds, SCC is generally recorded monthly, resulting in approximately 12 SCC test-day records per cow. Monthly SCC recordings may not always detect elevated somatic cells due to CM (Rupp and Boichard, 1999), because a mastitis infection can occur and the animal restored to health within a 1-mo period (Vaarst and Enevoldsen, 1997). In the present study, the number of SCC testday records per cow ranged from 10 to 52 , with an average of 31 SCC records. This increases the likelihood that elevations in SCC caused by infections of short duration, such as CM caused by Escherichia coli (de Haas et al., 2002; Burvenich et al., 2003; Bannerman et al., 2004) were included.

\section{LASCS and SCS-SD}

The LASCS is often calculated as the average of the log-transformed test-day SCC (Mark et al., 2002). Our preference, however, was to average test-day SCC first and then log-transform the data, because the influence of elevated test-day SCC on lactation-average SCC, and thus on LASCS, is larger by this method (de Haas et al., 2008). Moreover, the genetic correlation between the log-transformed average of test-day SCC and CM was found to be higher than the genetic correlation between the traditionally used average of the log-transformed test-day SCC and CM (de Haas et al., 2008). The SCS-SD was also chosen as a trait for analysis to capture variation in SCC levels of individual cows. For instance, cows can have the same lactation-average SCC but very different patterns of variation around the mean because of differences in infection status. Urioste et al. (2010) found that, in general, cows without any $\mathrm{CM}$ episode tend to have a relatively low variation in SCC and that these animals show faster recovery when infected.

\section{Genetic Parameters}

The estimated heritabilities using the RobustMilk data set were in good agreement with previously reported estimates. For example, the heritability of 0.17 for first-lactation LASCS was also reported previously by Rupp and Boichard (1999) and Mrode and Swanson (2003). Heritabilities reported in other studies are of the same approximate magnitude (e.g., Carlén et al., 2004; Heringstad et al., 2008). The estimated heritability for SCS-SD in the present study was 0.14 and agreed well with the finding of Urioste et al. (2010), which was 0.10 for weekly recordings and 0.14 for monthly recordings. Although SCS-SD has been analyzed previously (Uri-

Table 5. Effect sizes per genotype class for SNP BTB-02087354 and ARS-BFGL-NGS-101491 significantly associated with the standard deviation for test-day SCS (corresponding SE in parentheses) for the combined RobustMilk data and for each separate country of origin

\begin{tabular}{lrrrrrrr}
\hline & \multicolumn{3}{c}{ ARS-BFGL-NGS-101491 } & & \multicolumn{2}{c}{ BTB-02087354 $4^{1}$} \\
\cline { 2 - 3 } \cline { 6 - 7 } Data & \multicolumn{2}{c}{ AA } & AB & BB & & AA & AB \\
\hline RobustMilk & $0.50(0.21)$ & 0 & $-0.42(0.11)$ & & 0 & $1.20(0.24)$ \\
Ireland & $0.77(0.34)$ & 0 & $-0.30(0.20)$ & & 0 & $1.65(0.37)$ \\
The Netherlands & $0.82(0.36)$ & 0 & $-0.35(0.36)$ & & 0 & $1.45(0.45)$ \\
Scotland & $-0.19(0.45)$ & 0 & $-0.32(0.21)$ & & 0 & $0.50(0.57)$ \\
Sweden & $0.10(0.66)$ & 0 & $-0.77(0.65)$ & & 0 & $-0.14(0.70)$ \\
\hline
\end{tabular}

${ }^{1} \mathrm{SNP}$ consisted of 2 genotype classes. 
oste et al., 2010), the present study is the first to report the genetic correlation coefficient between LASCS and SCS-SD, which was 0.96 with an upper $95 \%$ limit of 1.0 and a lower $95 \%$ limit of 0.88 . This indicates that the genetic component of these 2 traits was not significantly different.

\section{GWAS}

The present study detected few SNP associations with LASCS or SDS-SD, which indicates that effects of most QTL involved in genetic control of LASCS and SCS-SD were not large enough to be detected with the traits defined in the present data set. First, this could suggest that the present data set may not provide sufficient power to detect loci with relatively small effects for the currently defined traits. The detection power of GWAS, especially for low to moderately heritable polygenic traits, would likely be substantially increased by including a larger number of animals. Detection of few genomic regions involved in genetic regulation of SCS or SCS-related traits is supported by other studies (e.g., Heyen et al., 1999; Klungland et al., 2001; Meredith et al., 2010). This could also suggest that SCS may be influenced by multiple QTL dispersed throughout the genome, each with a relatively small effect, which hinders detection of genomic regions.

In accordance with the genetic correlation between LASCS and SCS-SD, GWAS results identified a SNP significantly associating with both LASCS and SCSSD. The SNP ARS-BFGL-NGS-101491 passed the 0.20 FDR threshold for both LASCS and SCS-SD, with the same direction of the effect and a similar $-\log _{10} P$-value for both traits. In addition, the SNP BTB-01841922 on BTA4 was found to be significantly associated with LASCS, with a $-\log _{10} P$-value of 5.7. The direction of the effect of this SNP for SCS-SD was the same as for LASCS, but the $-\log _{10} P$-value of 3.5 fell short of the 0.20 FDR threshold. Similarly, the SNP BTB-02087354 on BTA6 was found to be significantly associated with SCS-SD with a $-\log _{10} P$-value of 6.1. The direction of the effect for this SNP for LASCS was the same as for SCS-SD but once again the $-\log _{10} P$-value of 4.6 fell short of the 0.20 FDR threshold.

\section{Candidate Genes}

Genes within a window of 200,000 bp around the associated SNP were considered as candidates. At this distance, linkage disequilibrium $\left(\mathrm{r}^{2}\right)$ decreases to a value of approximately 0.3 (Khatkar et al., 2008). The 200,000bp window around SNP ARS-BFGL-NGS101491, which associated with both LASCS and SCS-SD, contained 8 genes. Six of these genes, SLC7A5, CA5A, RNF166, a)

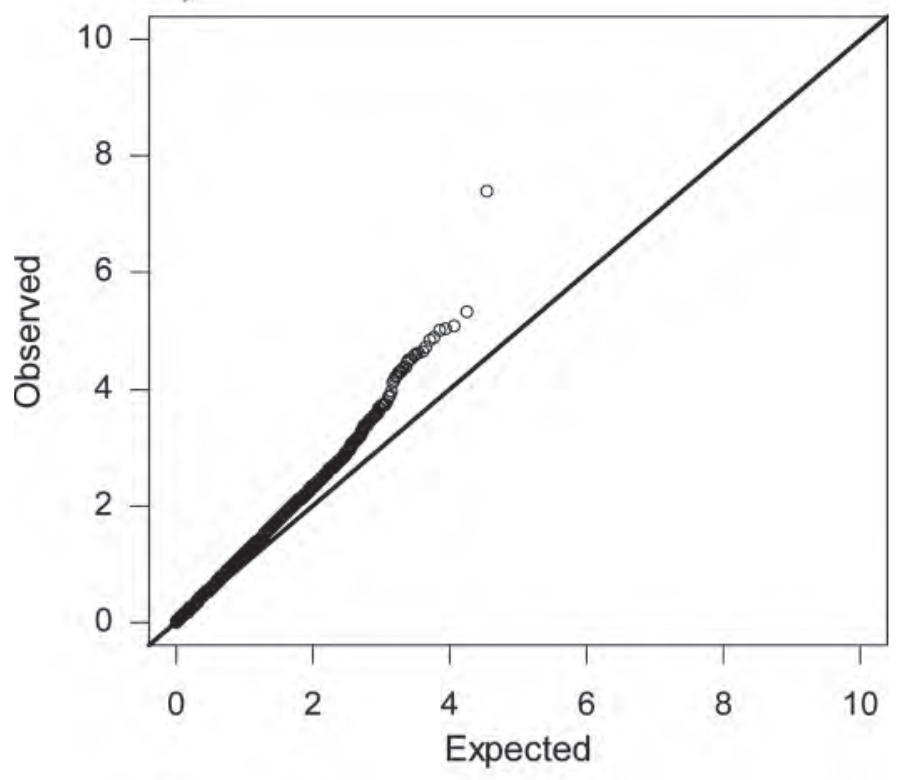

b)

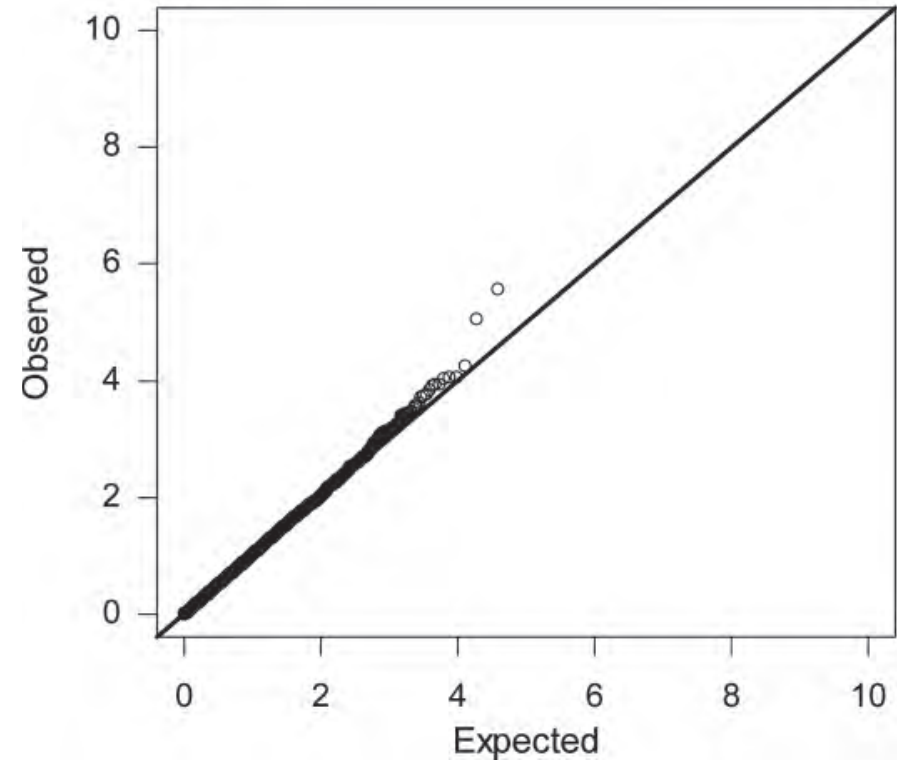

Figure 3. Quantile-quantile plot of the expected null distribution of the $P$-values versus the observed null distribution of the $P$-values for the lactation-average SCS, where (a) relationships between animals were not accounted for in the model and (b) relationships between animals were accounted for in the model.

MVD, CTU2, and SNAI3, have no apparent function in mastitis resistance. However, the bovine SMAR1 gene (GenBank accession no. BC119967.1) is located within this window. The gene product of SMAR1 plays a central role in cell cycle, apoptosis, and signaling pathways through its interaction with proteins such as nuclear factor $\kappa \mathrm{B}, \mathrm{p} 53$, and transforming growth factor- $\beta$ (Malonia et al., 2011). The p22-PHOX gene 
(GenBank accession no. AF036096.1) is located close to SNP ARS-BFGL-NGS-101491. The protein product of this gene plays a role in phagocytosis, as it is an essential component for an active phagocyte NADPH oxidase. This NADPH oxidase is required for the production of superoxide, a precursor of microbicidal oxidants (Sumimoto et al., 1996). A 200,000-bp window around SNP BTB-01841922 contained 4 genes, TFPI2, GNGT1, GNG11, and BET1, 3 of which are involved in functions relating to mastitis resistance. The GNGT1 and GNG11 genes code for G proteins, which function as signal transducers (Downes and Gautam, 1999) involved in regulation of cell migration and adhesion (Ahmed et al., 2010), key attributes of innate immune responses (Snyderman and Goetzl, 1981). The TFPI2 gene (GenBank accession no. AY234861.1) codes for a protein that plays a role in proliferation and apoptosis of smooth muscle cells (Ekstrand et al., 2010). The mammary gland contains smooth muscle-like myoepithelial cells whose protein expression resembles that of smooth muscle cells (Deugnier et al., 1995). Given this resemblance, the TFPI2 gene product may also exert influence on mammary tissue. No genes were present within a 200,000-bp window around SNP BTB02087354 .

\section{Comparison with Literature}

Multiple studies have identified regions containing QTL underlying genetic variation for SCS on almost all bovine chromosomes (Rupp and Boichard, 2003; Khatkar et al., 2004; Hu and Reecy, 2007). Chromosomes 1, 18, 21, and 23 are frequently reported to contain QTL for SCS (Rupp and Boichard, 2003; Khatkar et al., 2004). Previously, linkage studies have reported QTL for SCS on BTA4 (Zhang et al., 1998; Tal-Stein et al., 2010) and BTA 6 (Daetwyler et al., 2008; Lund et al., 2008). These QTL, however, do not appear to be in close proximity to SNP BTB-01841922 and SNP BTB02087354. Furthermore, linkage studies have reported a QTL for SCC and CM on BTA18 near the microsatellite marker TGLA227, located at approximately 65,000,000 bp (Bennewitz et al., 2003; Kühn et al., 2003; Schulman et al., 2004). This QTL could not be confirmed in the present GWAS.

From linkage studies, the magnitude of associations between phenotypes and genetic markers may be largely influenced by environmental factors (e.g., infection pressure) and the genetic background specific to studied populations and breeds (Rupp and Boichard, 2003). The results of GWAS may be subjected to the same limitations. From GWAS with 1,341 SNP, Kolbehdari et al. (2009) identified 2 SCS-associated SNP on BTA18 located at $807,748 \mathrm{bp}$ and $1,414,404 \mathrm{bp}$. The
SNP ARS-BFGL-NGS101491 associating with LASCS and SCS-SD in the present study was not located in the same region, given its position at 13,839,646 bp. A GWAS with 17,349 SNP performed by Sodeland et al. (2011) on Norwegian Red dairy cattle showed associations with daughter yield deviations for LASCS and CM on BTA12, BTA19, and BTA20. None of these associations was detected in the present study.

\section{CM and Production Traits}

The RobustMilk data set contains 390 cows that were part of 2 genetic lines (Scottish data) (Veerkamp et al., 1994). One line was selected for kilograms of milk fat plus protein and the other line was selected to resemble the average genetic merit for milk fat plus protein for all UK evaluated cows. A genetic antagonism has been described between SCC and production traits (e.g., Rupp and Boichard, 1999; Carlén et al., 2004). Phenotypic differences in LASCS and SCS-SD were, however, small between the 2 lines and no differences in MAF could be detected for the significant SNP.

In contrast, SCC and the occurrence of mastitis show a strong positive genetic correlation (e.g., Rupp and Boichard, 1999; Carlén et al., 2004; Koivula et al., 2005). Clinical mastitis records were available for RobustMilk cows from Scotland and Sweden. In total, 98 cows had a case of $\mathrm{CM}$ recorded during the first lactation (mastitic cows); the remaining 483 cows from Sweden and Scotland without such a record were assumed free of CM during this period (nonmastitic cows). Clear phenotypic differences in SCS were found between mastitic and nonmastitic cows; the average LASCS was 7.1 for mastitic and 6.1 for nonmastitic cows, and the average SCS-SD was 7.8 for mastitic and 5.9 for nonmastitic cows. The MAF for the significant SNP, however, did not differ between mastitic and nonmastitic cows. For SNP ARS-BFGL-NGS-101491 on BTA18, the frequency of the unfavorable allele was 0.25 in mastitic cows and 0.24 in nonmastitic cows. For SNP BTB-02087354 on BTA4, the frequency of the unfavorable allele was 0.02 in both mastitic and nonmastitic cows. For SNP BTB-01841922 on BTA6, the favorable allele had a frequency of 0.09 in mastitic cows and 0.07 in nonmastitic cows. In agreement with other studies (Klungland et al., 2001; Sodeland et al., 2011), these results suggest that the SNP associated with LASCS or SCS-SD do not have major effects on CM. One explanation is that LASCS is an average value of multiple test-day records and therefore not directly comparable with CM records (Sodeland et al., 2011). In addition, the traits measure separate aspects of udder health (Lund et al., 2007), which results in a loss of statistical power (Lund et al., 2007; Sodeland et al., 2011). Furthermore, SNP effects 
on LASCS and SCS-SD in the present study were relatively small. Therefore, if an association of these SNP exists with CM, the difference in allele frequency would have a minor effect on the phenotype.

\section{CONCLUSIONS}

The present study is one of the first studies to combine detailed phenotypic and genotypic cow data from research herds located in different countries. Relatively few associated SNP were found, which suggests that LASCS and SCS-SD are controlled by multiple loci, each with a relatively small effect, distributed across the genome, although the number of animals included in the study was relatively small. Findings from the present study need to be verified in subsequent independent studies. More knowledge on genetic control of LASCS and SCS-SD is needed to enable a greater selection response for these traits. Such knowledge could be particularly valuable for improvement of the accuracy of EBV for bull dams. Moreover, such knowledge contributes to the quest for genes for mastitis resistance and aids in our understanding of the genetic mechanisms of mastitis and the discovery of targets for mastitis therapeutics.

\section{ACKNOWLEDGMENTS}

This work was carried out as part of the RobustMilk project that is financially supported by the European Commission under the Seventh Research Framework Programme, Grant Agreement KBBE-211708. The content of this paper is the sole responsibility of the authors, and it does not necessarily represent the views of the Commission or its services.

\section{REFERENCES}

Ahmed, S. M., A. M. Daulat, A. Meunier, and S. Angers. 2010. G protein $\beta \gamma$ subunits regulate cell adhesion through Rapla and its effector Radil. J. Biol. Chem. 285:6538-6551. doi:10.1074/jbc. M109.069948.

Ali, A. K. A., and G. E. Shook. 1980. An optimum transformation for somatic cell concentration in milk. J. Dairy Sci. 63:487-490. doi:10.3168/jds.S0022-0302(80)82959-6.

Bannerman, D. D., M. J. Paape, J. Lee, X. Zhao, J. C. Hope, and P. Rainard. 2004. Escherichia coli and Staphylococcus aureus elicit differential innate immune response following intramammary infection. Clin. Diagn. Lab. Immunol. 11:463-472. doi:10.1128/ CDLI.11.3.463-472.2004.

Bell, M. J., E. Wall, G. Russell, G. Simm, and A. W. Stott. 2011. The effect of improving cow productivity, fertility and involuntary culling on the global warming potential of dairy systems. J. Dairy Sci. 94:3662-3678. doi:10.3168/jds.2010-4023.

Bennewitz, J., N. Reinsch, C. Grohs, H. Levéziel, A. Malafosse, H. Thomsen, N. Xu, C. Looft, C. Kühn, G. A. Brockmann, M. Schwerin, C. Weinmann, S. Hiendleder, G. Erhardt, I. Medjugorac, I. Russ, M. Förster, B. Brenig, F. Reinhardt, R. Reents, G. Aver- dunk, J. Blümel, D. Boichard, and E. Kalm. 2003. Combined analysis of data from two granddaughter designs: A simple strategy for QTL confirmation and increasing experimental power in dairy cattle. Genet. Sel. Evol. 35:319-338. doi:10.1051/gse:2003011.

Burvenich, C., V. van Merris, J. Mehrzad, A. Diez-Fraile, and L. Duchateau. 2003. Severity of $E$. coli mastitis is mainly determined by cow factors. Vet. Res. 34:521-564. doi:10.1051/vetres:2003023.

Calus, M. P. L., H. A. Mulder, and J. W. M. Bastiaansen. 2011. Identification of Mendelian inconsistencies between SNP and pedigree information of sibs. Genet. Sel. Evol. 43:34.

Carlén, E., E. Strandberg, and A. Roth. 2004. Genetic parameters for clinical mastitis, somatic cell score, and production in the first three lactations of Swedish Holstein cows. J. Dairy Sci. 87:30623070. doi:10.3168/jds.S0022-0302(04)73439-6.

Daetwyler, H. D., F. S. Schenkel, M. Sargolzaei, and J. A. B. Robinson. 2008. A genome scan to detect quantitative trait loci for economically important traits in Holstein cattle using two methods and a dense single nucleotide polymorphism map. J. Dairy Sci. 91:3225-3236. doi:10.3168/jds.2007-0333.

de Haas, Y., H. W. Barkema, Y. H. Schukken, and R. F. Veerkamp. 2003. Genetic associations for pathogen-specific clinical mastitis and patterns of peaks in somatic cell count. Anim. Sci. 77:187195.

de Haas, Y., H. W. Barkema, and R. F. Veerkamp. 2002. Effect of pathogen-specific clinical mastitis on lactation curves for somatic cell count. J. Dairy Sci. 85:1314-1323. doi:10.3168/jds.S00220302(02)74196-9.

de Haas, Y., W. Ouweltjes, J. ten Napel, J. J. Windig, and G. de Jong. 2008. Alternative somatic cell count traits as mastitis indicators for genetic selection. J. Dairy Sci. 91:2501-2511. doi:10.3168/ jds.2007-0459.

Detilleux, J. C. 2009. Genetic factors affecting susceptibility to udder pathogens. Vet. Microbiol. 134:157-164. doi:10.1016/j.vetmic.2008.09.023.

Deugnier, M. A., E. P. Moiseyeva, J. P. Thiery, and M. Glukhova. 1995. Myoepithelial cell differentiation in the developing mammary gland: Progressive acquisition of smooth muscle phenotype. Dev. Dyn. 204:107-117. doi:10.1002/aja.1002040202.

Downes, G. B., and N. Gautam. 1999. The G protein subunit gene families. Genomics 62:544-552. doi:10.1006/geno.1999.5992

Ekstrand, J., A. Razuvaev, L. Folkersen, J. Roy, and U. Hedin. 2010. Tissue factor pathway inhibitor-2 is induced by fluid shear stress in vascular smooth muscle cells and affects cell proliferation and survival. J. Vasc. Surg. 52:167-175. doi:10.1016/j.jvs.2010.02.282.

Gilmour, A. R. B. J. Gogel, B. R.Cullis, and R. Thompson. 2009. ASReml User Guide. Release 3.0. VSN International Ltd., Hemel Hempstead, UK.

Green, M. J., L. E. Green, Y. H. Schukken, A. J. Bradley, E. J. Peeler, H. W. Barkema, Y. de Haas, V. J. Collis, and G. F. Medley. 2004 Somatic cell count distributions during lactation predict clinical mastitis. J. Dairy Sci. 87:1256-1264. doi:10.3168/jds.S00220302(04)73276-2.

Hayes, B. J., P. J. Bowman, A. J. Chamberlain, and M. E. Goddard. 2009. Invited review: Genomic selection in dairy cattle: Progress and challenges. J. Dairy Sci. 92:433-443. doi:10.3168/jds.20081646 .

Heringstad, B., E. Sehested, and T. Steine. 2008. Short communication: Correlated selection responses in somatic cell count from selection against clinical mastitis. J. Dairy Sci. 91:4437-4439. doi:10.3168/jds.2008-1330.

Heyen, D. W., J. I. Weller, M. Ron, M. Band, J. E. Beever, E. Feldmesser, Y. Da, G. R. Wiggans, P. M. VanRaden, and H. A. Lewin. 1999. A genome scan for QTL influencing milk production and health traits in dairy cattle. Physiol. Genomics 1:165-175.

Hirschhorn, J. N., and M. J. Daly. 2005. Genome-wide association studies for common diseases and complex traits. Nat. Rev. Genet. 6:95-108. doi:10.1038/nrg1521.

Hu, Z. L., and J. M. Reecy. 2007. Animal QTLdb: Beyond a repository. A public platform for QTL comparisons and integration with diverse types of structural genomic information. Mamm. Genome 18:1-4. doi:10.1007/s00335-006-0105-8. 
Khatkar, M. S., F. W. Nicholas, A. R. Collins, K. R. Zenger, J. A. L. Cavanagh, W. Barris, R. D. Schnabel, J. F. Taylor, and H. W. Raadsma. 2008. Extent of genome-wide linkage disequilibrium in Australian Holstein-Friesian cattle based on a high-density SNP panel. BMC Genomics doi:10.1186/1471-2164-9-187.

Khatkar, M. S., P. C. Thomson, I. Tammen, and H. W. Raadsma. 2004. Quantitative trait loci mapping in dairy cattle: Review and meta-analysis. Genet. Sel. Evol. 36:163-190. doi:10.1051/ gse:2003057.

Klungland, H., A. Sabry, B. Heringstad, H. G. Olsen, L. Gomez-Raya, D. I. Våge, I. Olsaker, J. Ødegård, G. Klemetsdal, N. Schulman, J. Vilkki, J. Ruane, M. Aasland, K. Rønningen, and S. Lien. 2001. Quantitative trait loci affection clinical mastitis and somatic cell count in dairy cattle. Mamm. Genome 12:837-842. doi:10.1007/ s00335001-2081-3.

Koivula, M., E. A. Mäntysaari, E. Negussie, and T. Serenius. 2005. Genetic and phenotypic relationships among milk yield and somatic cell count before and after clinical mastitis. J. Dairy Sci. 88:827-833. doi:10.3168/jds.S0022-0302(05)72747-8.

Kolbehdari, D., Z. Wang, J. R. Grant, B. Murdoch, A. Prasad, Z. Xiu, E. Marques, P. Stothard, and S. S. Moore. 2009. A whole genome scan to map QTL for milk production traits and somatic cell score in Canadian Holstein bulls. J. Anim. Breed. Genet. 126:216-227. doi:10.1111/j.1439-0388.2008.00793.x.

Kühn, C., J. Bennewitz, N. Reinsch, N. Xu, H. Thomsen, C. Looft, G. A. Brockmann, M. Schwerin, C. Weimann, S. Hiendleder, G. Erhardt, I. Medjugorac, M. Förster, B. Brenig, F. Reinhardt, R. Reents, I. Russ, G. Averdunk, J. Blümel, and E. Kalm. 2003. Quantitative trait loci mapping of functional traits in the German Holstein cattle population. J. Dairy Sci. 86:360-368. doi:10.3168/ jds.S0022-0302(03)73614-5.

Lund, M. S., B. Guldbrandtsen, A. J. Buitenhuis, B. Thomsen, and C. Bendixen. 2008. Detection of quantitative trait loci in Danish Holstein cattle affecting clinical mastitis, somatic cell score, udder conformation traits, and assessment of associated effects on milk yield. J. Dairy Sci. 91:4028-4036. doi:10.3168/jds.2007-0290.

Lund, M. S., G. Sahana, L. Andersson-Eklund, N. Hastings, A. Fernandez, N. Schulman, B. Thomsen, S. Viitala, J. L. Williams, A. Sabry, H. Viinalass, and J. Vilkki. 2007. Joint analysis of quantitative trait loci for clinical mastitis and somatic cell score on five chromosomes in three Nordic dairy cattle breeds. J. Dairy Sci. 90:5282-5290. doi:10.3168/jds.2007-0177.

Malonia, S. K., S. Sinha, P. Lakshminarasimhan, K. Singh, A. JalotaBadhwar, S. Rampalli, R. Kaul-Ghanekar, and S. Chattopadhyay. 2011. Gene regulation by SMAR1: Role in cellular homeostasis and cancer. Biochim. Biophys. Acta 1815:1-12. doi:10.1016/j. bbcan.2010.08.003.

Mark, T., W. F. Fikse, U. Emanuelson, and J. Philipsson. 2002. International genetic evaluation of Holstein sires for milk somatic cell and clinical mastitis. J. Dairy Sci. 85:2384-2392. doi:10.3168/jds. S0022-0302(02)74319-1.

Matukumalli, L. K., C. T. Lawley, R. D. Schnabel, J. F. Taylor, M. F. Allan, M. P. Heaton, J. O'Connell, S. S. More, T. P. L. Smith, T. S. Sonstegard, and C. P. Van Tassell. 2009. Development and characterization of a high density SNP genotyping assay for cattle. PLoS ONE 4:e5350 doi:10.1371/journal.pone.0005350.

McCarthy, S., D. P. Berry, P. Dillon, M. Rath, and B. Horan. 2007. Effect of strain of Holstein-Friesian and feed system on udder health and milking characteristics. Livest. Sci. 107:1-28. doi:10.1016/j. livsci.2006.08.014.

Meredith, B. K., J. F. Kearney, and D. P. Berry. 2010. Genome-wide associations for milk production and somatic cell count in Irish Holstein-Friesian cattle. Pdf 0737 in Proc. 9th World Conference on Genetics Applied to Livestock Production, Leipzig, Germany. Gesellschaft für Tierzuchtwissenschaften e.V., Giessen, Germany.

Miglior, F., B. L. Muir, and B. J. Van Doormaal. 2005. Selection indices in Holstein cattle of various countries. J. Dairy Sci. 88:12551263. doi:10.3168/jds.S0022-0302(05)72792-2.
Mrode, R. A., and G. J. T. Swanson. 2003. Estimation of genetic parameters for somatic cell count in the first three lactations using random regression. Livest. Prod. Sci. 79:239-247. doi:10.1016/ S0301-6226(02)00169-0.

Petersson, K. J., H. Gustafsson, E. Strandberg, and B. Berglund. 2006. Atypical progesterone profiles and fertility in Swedish dairy cows. J. Dairy Sci. 89:2529-2538. doi:10.3168/jds.S0022-0302(06)723281.

Pryce, J. E., S. Bolormaa, A. J. Chamberlain, P. J. Bowman, K. Savin, M. E. Goddard, and B. J. Hayes. 2010. A validated genome-wide association study in 2 dairy cattle breeds for milk production and fertility traits using variable length haplotypes. J. Dairy Sci. 93:3331-3345. doi:10.3168/jds.2009-2893.

Rupp, R., and D. Boichard. 1999. Genetic parameters for clinical mastitis, somatic cell score, production, udder type traits, and milking ease in first lactation Holsteins. J. Dairy Sci. 82:2198-2204. doi:10.3168/jds.S0022-0302(99)75465-2.

Rupp, R., and D. Boichard. 2003. Genetics of resistance to mastitis in dairy cattle. Vet. Res. 34:671-688. doi:10.1051/vetres:2003020.

Rupp, R., A. Hernandez, and B. A. Mallard. 2007. Association of bovine leukocyte antigen (BoLA) DRB3.2 with immune response, mastitis, and production and type traits in Canadian Holsteins. J. Dairy Sci. 90:1029-1038. doi:10.3168/jds.S0022-0302(07)71589-8.

Schulman, N. F., S. M. Viitala, D. J. de Koning, J. Virta, A. MäkiTanilla, and J. H. Vilkki. 2004. Quantitative trait loci for health traits in Finnish Ayrshire cattle. J. Dairy Sci. 87:443-449. doi:10.3168/jds.S0022-0302(04)73183-5.

Snyderman, R., and E. J. Goetzl. 1981. Molecular and cellular mechanisms of leukocyte chemotaxis. Science 213:830-837.

Sodeland, M., M. P. Kent, H. G. Olsen, M. A. Opsal, M. Svendsen, E. Sehested, B. J. Hayes, and S. Lien. 2011. Quantitative trait loci for clinical mastitis on chromosomes 2, 6, 14 and 20 in Norwegian Red cattle. Anim. Genet. 42:457-465. doi:10.1111/j.13652052.2010.02165.x.

Storey, J. D., and R. Tibshirani. 2003. Statistical significance for genomewide studies. Proc. Natl. Acad. Sci. USA 100:9440-9445. doi:10.1073/pnas.1530509100.

Sumimoto, H., K. Hata, K. Mizuki, T. Ito, Y. Kage, Y. Sakaki, Y. Fukumaki, M. Nakamura, and K. Takeshige. 1996. Assembly and activation of the phagocyte NADPH oxidase. J. Biol. Chem. 271:22152-22158. doi:10.1074/jbc.271.36.22152.

Tal-Stein, R., L. Fontanesi, M. Dolezal, E. Scotti, A. Bagnato, V. Russo, F. Canavesi, A. Friedmann, M. Soller, and E. Lipkin. 2010. A genome scan for quantitative trait loci affection milk somatic cell score in Israeli and Italian Holstein cows by means of selective DNA pooling with single- and multiple-marker mapping. J. Dairy Sci. 93:4913-4927. doi:10.3168/jds.2010-3254.

Urioste, J. I., J. Franzén, and E. Strandberg. 2010. Phenotypic and genetic characterization of novel somatic cell count traits from weekly or monthly observations. J. Dairy Sci. 93:5930-5941. doi:10.3168/jds.2010-3301.

Vaarst, M., and C. Enevoldsen. 1997. Patterns of clinical mastitis manifestations in Danish organic dairy herds. J. Dairy Res. 64:23-37.

Veerkamp, R. F., J. K. Oldenbroek, H. J. Van Der Gaast, and J. H. J. Van Der Werf. 2000. Genetic correlation between days until start of luteal activity and milk yield, energy balance, and live weights. J. Dairy Sci. 83:577-583. doi:10.3168/jds.S0022-0302(00)74917-4.

Veerkamp, R. F., G. Simm, and J. D. Oldham. 1994. Effects of interaction between genotype and feeding system on milk production, feed intake, efficiency and body tissue mobilization in dairy cows. Livest. Prod. Sci. 39:229-241. doi:10.1016/0301-6226(94)90202-X.

Zhang, Q., D. Boichard, I. Hoeschele, C. Ernst, A. Eggen, B. Murkve, M. Pfister-Genskow, L. A. Witte, F. E. Grignola, P. Uimari, G. Thaller, and M. D. Bishop. 1998. Mapping quantitative trait loci for milk production and health of dairy cattle in a large outbred pedigree. Genetics 149:1959-1973. 